\title{
EDITORS' CORNER
}

A

$s$ we begin our new term as $P S$ editors, we are excited to announce a few changes to the journal which we are adopting in response to discussions with our editorial board, the APSA Council's publication subcommittee, and APSA members.

\section{SYMPOSIUM POLICY}

Symposia have become an increasingly prominent part of $P S$, and we receive very positive feedback from our readers about them. Outside of edited volumes, there are few outlets in our discipline for a set of focused articles on a single topic. At the same time, during the evaluation process, we wrestled with how to balance symposia with our stated goals of diversifying and expanding our pool of authors.

Achieving diversity and inclusion is a priority for the American Political Science Association. As part of this commitment, $P S$ now requests that scholars proposing a symposium consider how they may contribute to this effort by recruiting participants with a diverse set of scholarly backgrounds, methodological perspectives, and from groups that have been traditionally underrepresented in political science.
Future symposium proposals must include a brief description of the guest editor's efforts to recruit a broad and diverse team of contributors.

In addition, we were asked to make certain that our peer-review process was transparent and equitable. In response, all articles, including symposia, will undergo a double-blind peer review. (Guest editors were previously provided the option of utilizing a single-blind review process.)

\section{THE TEACHER}

Starting in January 2018, manuscripts submitted for review with $P S$ under the teaching section will be evaluated under one of two categories.

Manuscripts submitted under the Scholarship of Teaching and Learning category will be expected to meet the SoTL standards providing rigorous, systematic, and evidence-based assessments of teaching goals. SoTL research may include but is not limited to questionnaires and surveys, reflection and analysis, interviews and focus groups, content analysis of text, secondary analysis of existing data, quasi-experiments (e.g., comparison of two sections of the same course), and case studies. Submissions can be diverse in terms of topic but must provide, either quantitatively or qualitatively, evidence demonstrating the pedagogical innovations or teaching techniques described in the manuscript are effective. SoTL manuscripts must be under 3,650 words including the abstract, references, and tables.

Teaching Innovation submissions will focus on new, creative or experimental teaching, including innovative strategies, games, software, and experiential learning to improve classroom and co-curricular learning experiences for teaching political science. Manuscripts submitted in the Teaching Innovations category are not expected to provide the systematic assessment required of traditional SOTL research. Submissions may range in length from 750-1,250 words.

We would like to thank the editorial team of Journal of Political Science Education for helping us establish review criteria for these new categories, which correspond closely to manuscript categories used by JPSE.

-Phillip Ardoin
Appalachian State University
-Paul Gronke
Reed College




\section{APSA Mentoring Program}

\section{Find a Mentor or Become a Mentor}

APSA is seeking additional mentors to provide professional advice to undergraduates, graduate students, and junior faculty in the profession. The APSA Mentoring Program is an opportunity for all political scientists to network and share experience, advice and insights about career planning, scholarship, and a variety of professional issues such as:

\section{- Selecting a dissertation committee}

- Publishing and research

- Non-academic careers

- Life as junior faculty member

- Balancing family and work

The APSA mentoring database includes mentors with a wide variety of expertise and fields of interest. APSA is looking for additional mentors in non-academic careers and international relations, and to mentor Ralph Bunche Scholars (RBSI) and/or APSA Minority Fellows (MFP).

\section{Use the online submission form to become or request a mentor!}

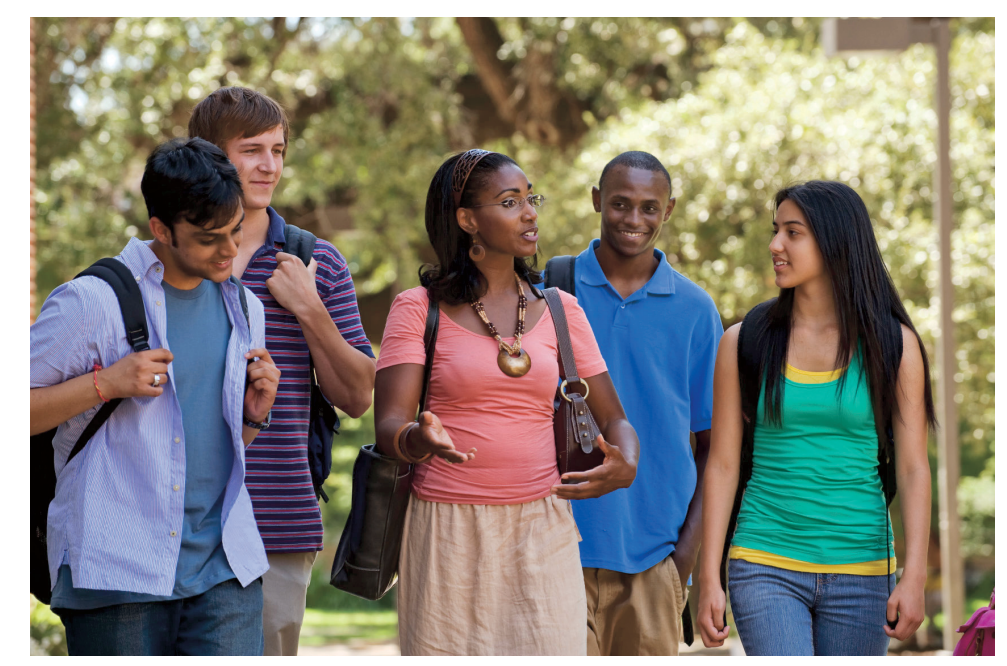

\section{Sign up at www.apsanet.org/mentor.}

